\title{
Study on Agricultural Products Logistics Cost Control Based on the Internet of Things
}

\author{
Wenfeng Liu \\ School of Tianjin University of Technology, Tianjin 300384, China \\ liuwenfeng1990@126.com
}

Keywords: Agricultural products, Logistics cost, Internet of things.

\begin{abstract}
In recent years, agricultural prices rising, one reason is the high cost of logistics. With more and more widely the application scope of the Internet of things technology, it brings to reduce logistics cost. Based on the analysis of development situation of the Internet of things and agricultural products logistics, we can establish agricultural products logistics information system, realize information sharing and improve the monitoring ability of the agricultural products. At the same time, we need to control each link of the logistics cost, improve the efficiency of logistics, reduce logistics cost.
\end{abstract}

\section{Introduction}

During the next National Twelfth Five-Year Plan period, the Internet of things start to entere the stage of scale development. Developed countries on the one hand, intensify efforts to develop core chip, embedded operating system, intelligent sensor node calculation such as the core technology, and on the other hand accelerate the industrialization process standards, for large-scale development of the Internet of things in the future and occupy the favorable position in international competition.The development and application of Internet technology, not only brings the economic benefits of efficiency, innovation, etc, also through informatization level to promote social production mode and management mode to become intelligent and refinement.At the same time, modern logistics is the inevitable outcome of the development of market economy, through to organic integration of the functional elements such as the transportation, storage, loading and unloading, packaging, circulation processing and information, effectively realize the value of time and space.

In January 2013, the ministry of industry and information technology of the people's republic of China republic the work guidance to remote the logistics informationization, and by the end of the National Twelfth Five-Year, we should preliminary build compatible with national modern logistics system and the coordinated development of logistics information system, improve the level of socialization, marketization development, and actively promote the Internet of things, cloud computing and other new technology to apply in the field of logistics.

\section{The concept of Internet of Things and development status}

\subsection{The concept of Internet of Things}

Internet of Thing was first proposed by the United States. It was named Internet of Thing at "World Summit of Information Society" in 2005.The Internet of things is a kind of Internet to connect objects, which is the inevitable outcome of the next generation network and Internet development. Internet of things through the laser scanner information sensing devices such as the radio frequency identification (RFID), wireless communication technology, GPS technology, infrared sensors, formulated according to the agreement, the relevant people, objects connected with the Internet, According to the agreement to connected to people, objects and internet, exchange of information and communications and will constitute a social perception with the Thing to Thing, the Human to Thing, person to the Human to Human.

From the technical architecture point of view, it can be divided into three layers: the perception layer, network layer and application layer. The perception layer is composed of a variety of sensors 
and sensor gateways. It uses RFID technology, sensor network technology (WSN), GPS satellite positioning technology, M2M data communications technology, object recognition, collection of information, which belongs to infrastructure layer on the networking industry chain infrastructure layer. Network layer is composed of a variety of private networks, the Internet, wired and wireless communication networks, network management systems and cloud computing platforms, responsible for transmission and processing of information perception layer acquisition. Networking and application layer is the user interface, which combined with the industry needs to realize intelligent networking applications.

\subsection{The Internet of things industry development status}

Synchronize with the world the development of the Internet of things industry basic, industry scale unceasingly growing, and rapidly expanding application areas. In 2013, Internet industry scale of about 500 billion yuan in China, annual growth rate of about $36.9 \%$.It is expected that the industry will exceed 700 billion yuan in 2015, an average annual compound growth rate of more than $30 \%$.

\section{Agricultural products logistics development status}

\subsection{The concept of agricultural products logistics}

Agricultural products logistics is to point to in order to meet user demand, realize the value of agricultural products and agricultural products material entity and related information from producers to consumers the logistics between the economic activity, it includes agricultural production, purchase, transportation, storage, loading and unloading, handling, packaging, distribution, circulation processing, distribution and information activities and a series of links, and in this process to realize the value of the agricultural product value-added and organizational goals.

\subsection{The present situation of the agricultural products logistics cost}

Agricultural products logistics in our country develop faster. Since the 2005-2014, agricultural products logistics the forehead is increasing year by year, but the logistics of agricultural products small proportion of total social logistics getting lower and lower that of agricultural products logistics development speed and overall social logistics development gap is widening (table1).In addition, the agricultural products logistics efficiency exist unbalanced development of our country, the central region development efficiency is higher, the eastern times, the lowest in the western conference. All these problems seriously affected the development of the logistics of agricultural products. According to statistics, China's logistics cost generally accounts for $20 \%$ of the total cost - 30\%, of which our country agricultural product cost occupy more than $40 \%$ of the whole cost, fresh products logistics cost is higher. Every year the loss of 12 million tons of fruit, vegetables one hundred million tons, foreign higher levels by more than 20\%.At the same time, extensive logistics mode of agricultural products, the ineffective logistics cost is higher.

Table 1 China's agricultural products logistics development trend from 2005-2014

\begin{tabular}{ccccc}
\hline Year & $\begin{array}{c}\text { The total amount of } \\
\text { agricultural logistics } \\
\text { (one trillion yuan) }\end{array}$ & $\begin{array}{c}\text { The total amount of } \\
\text { social logistics } \\
\text { (one trillion yuan) }\end{array}$ & $\begin{array}{c}\text { The proportion of } \\
\text { agricultural } \\
\text { products } \\
\text { logistics(\%) }\end{array}$ & $\begin{array}{c}\text { Agricultural produr } \\
\text { logistics year-on-yt } \\
\text { growth rate(\%) }\end{array}$ \\
\hline 2005 & 1.27 & 48.2 & 2.6 & 6.5 \\
2006 & 1.4 & 59.6 & 2.3 & 6.3 \\
2007 & 1.6 & 75.2 & 2.1 & 17.0 \\
2008 & 1.9 & 89.9 & 2.1 & 17.6 \\
2009 & 1.9 & 96.7 & 2.0 & 4.3 \\
2010 & 2.2 & 125.4 & 1.8 & 4.3 \\
2011 & 2.3 & 158.4 & 1.5 & 4.5 \\
2012 & 2.4 & 177.0 & 1.4 & 4.5 \\
2013 & 2.5 & 197.8 & 1.3 & 4.0 \\
2014 & 3.3 & 213.5 & 1.5 & 4.1 \\
\hline
\end{tabular}




\section{The construction of agricultural products logistics information system}

\subsection{The construction of agricultural products logistics system based on the technology of Internet of things}

The characteristics of Chinese current system of agricultural products, agricultural products of the requirements and differences between each link in the whole supply chain of agricultural products, information asymmetry, imperfect infrastructure, these three aspects are causing agricultural products logistics costs rise.And from the point of agricultural products circulation of agricultural products logistics cost, the whole to reduce logistics costs, agricultural products, application of Internet technology to establish agricultural products logistics information system is imperative. According to our country existing agricultural products logistics mode, namely agriculture from production to consumption of the whole process should be monitored, ability to control the cost of each link, agricultural products logistics information system model is established(Fig.1).

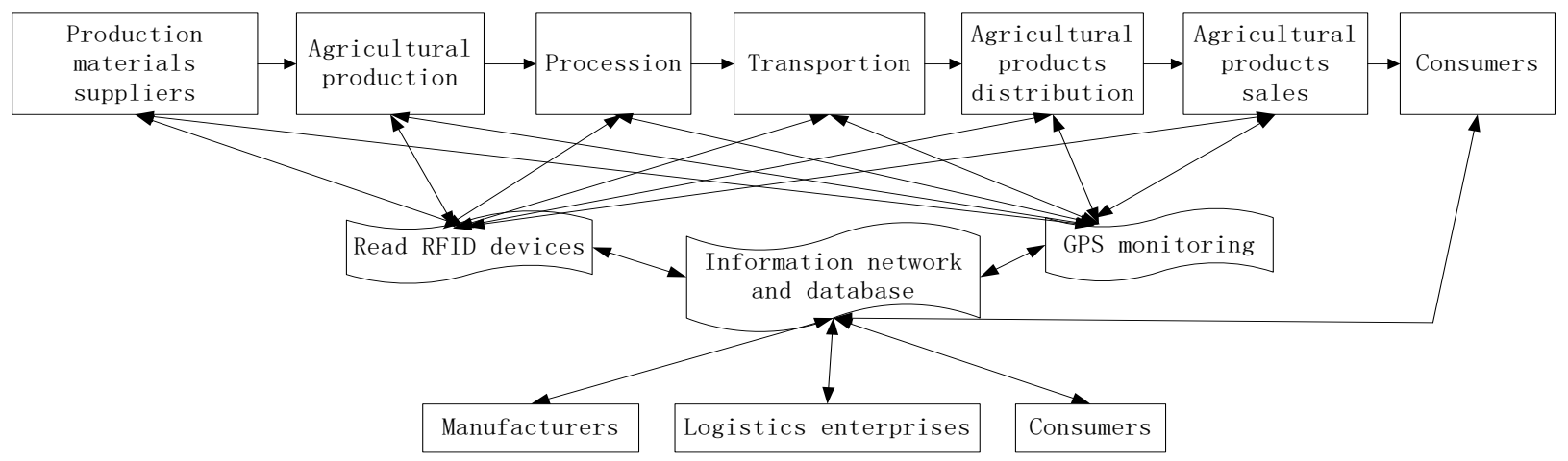

Fig. 1 The model of Agricultural products logistics information system

\subsection{The composition of the system}

The system includes production management subsystem, logistics tracking management subsystem, inventory management subsystem, four subsystem and information database query subsystem(Fig.2).

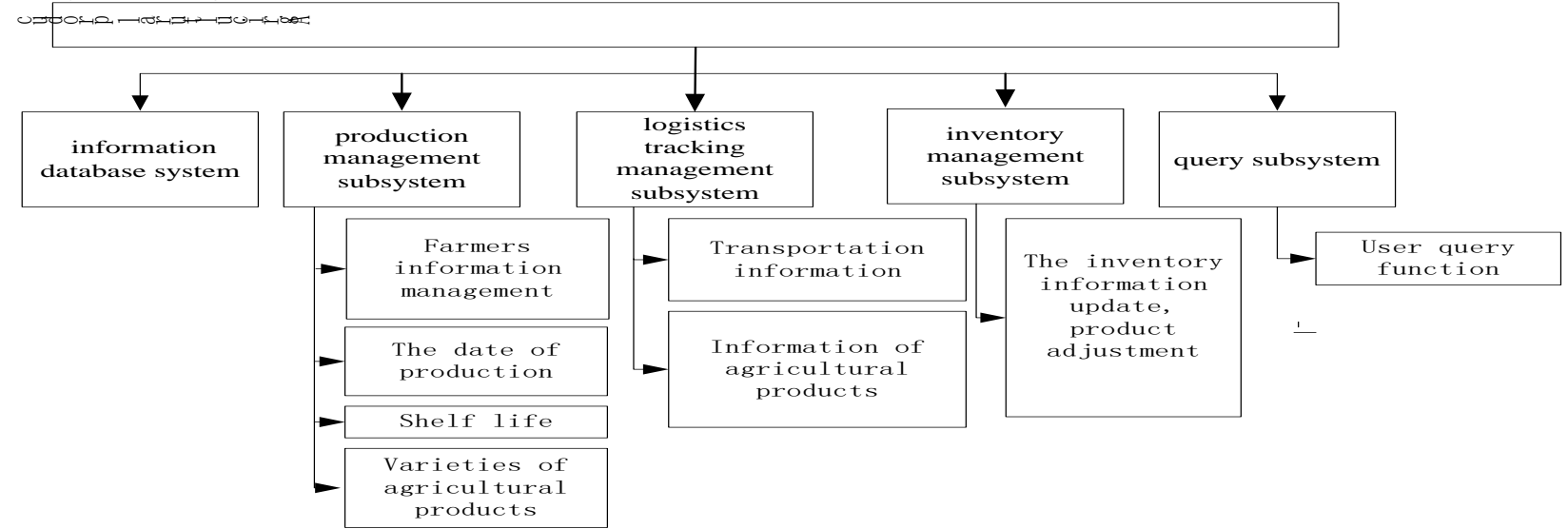

Fig. 2 Agricultural products logistics information system

Establish information database system. The system includes modules, supporting multiple subsystems for the realization of the function of data query, collection, etc. Such as through RFID equipment automated to collect data, and to filter the tag reading and writing data, specification data storage style sheets and data access operation, thus agricultural logistics chain multiparty real-time query and tracking of goods demand 
Production management subsystem. It main realizes agricultural products all of the production process of tracking and management. Agricultural information management module, including crop brand name, bar code, fertilizer application, picking time, production period, etc. Agricultural planting information module, including leaf number, location, area, etc,

The logistics tracking management subsystem.

(1) Transport link. The subsystem at the different stages of the circulation of agricultural products, based on the producing area, port, wharf and other gateway install RFID read-write equipment, timely records information, transmission and processing of agricultural products, and use of transport vehicles to install GPS system to accomplish the agricultural products, realize the data real-time updates.

(2) The distribution chain. EPC technology can accurately know the goods location, shorten the picking time, improve the picking accuracy, improve the picking efficiency, and speed the delivery up. At the same time, the conditions for timely and correctly master the number of agricultural products, transport, transshipment of provenance and destination and the information such as the expected time of arrival, to realize the remote control, reduce the risk of transportation.

(3) The sales link. When extracted by customers of the goods with EPC labels, smart shelves will automatically identify and report to the system, the logistics enterprises can implement agile reaction so that the logistics enterprises to better carry out active marketing and active service.

Inventory management subsystem. The system is mainly used for product delivery, receiving, inspection, warehousing, inventory, outbound automation management, automated inventory, pick up, quick inventory in the warehouse operation, etc. It improves the efficiency of the artificial stock, and saves the manpower cost. Through database reflects all kinds of information, help to monitor the supply of agricultural products quantity and inventory quantity, to achieve the timely replenishment, improve inventory management ability, can accurately according to the instruction Efficiently cherry-pick a variety of goods, reduce the unloading time, reduce inventory cost. At the same time also to deal with expired, rotting agricultural products, ensure the quality of agricultural products, improve the efficiency of the retailers and retail quality.

Query subsystem. Query subsystem supports manufacturers, logistics companies, distributors and consumers through the Internet of things, such as the user login interface and mobile query. Establish a query website and query system, through the integration of background management system and database system, updating accurate information of agricultural products.

\section{Summary}

Through the use of the Internet of things technology, breaking the traditional agricultural logistics in the process of production, purchasing, packaging, processing and circulation, storage and transportation sales process completely isolated mode, the Internet of things as basic data acquisition platform and set up new agricultural product logistics operation mode.Using this model can improve the information sharing which is not only make the sharing of information between agricultural producers and accelerate the enterprise internal logistics flow; also it improves the level of information resources sharingand saves investments between the seller and seller.

\section{References}

[1] Xiaohui Sun, Liqun Tan, Quanzhou Guo, et al. Study on quality and safety of agricultural products supply chain management [J].Value engineering.2009 No. 12, p. 82-85.

[2] Jing Liu, Xinyan Li. The Internet of things technology in the application of intelligent logistics [J]. Operators and managers.2012 No. 11, p. 257.

[3] Wei Zhang. Based on the Internet of things related to technology of intelligent traffic control system design [J]. Computer knowledge and technology.2011 No. 10, p. 2375-2376. 